\title{
A INFLUÊNCIA DE SER ATLETA NA IDENTIDADE SOCIAL DE PORTADORES DE DEFICIÊNCIA FÍSICA
}

\author{
The Influence of Being an Athlete over the Social Identity \\ of People with Physical Disabilities
}

\author{
Kleber Lopes Lima Fialho ${ }^{1}$ \\ Marcos Emanoel Pereira ${ }^{2}$
}

\section{Resumo}

O estudo busca evidenciar as diferenças nos padrões de respostas que sustentam uma percepção diferenciada de quatro categorias sociais distintas: a dos portadores de deficiência física não-atletas, a dos portadores de deficiência física atletas, a dos não portadores de deficiência física não-atletas e a dos não portadores de deficiência física atletas. Foram considerados os resultados que indicassem a influência de ser atleta no julgamento dos participantes em relação aos portadores de deficiência física, contando com uma amostra de 96 participantes. Utilizou-se um procedimento de escalonamento comparativo que permitiu a eles observar suas diversas respostas para cada item. Os resultados indicaram diferenças de julgamentos entre os grupos, principalmente em relação aos atletas portadores de deficiência física, avaliados mais positivamente que os portadores não-atletas e algumas vezes, surpreendentemente, mais do que o não portador, evidenciando uma idealização e superestimação da condição de ser atleta. Acredita-se que os resultados apresentados por esse estudo possam oferecer indícios para o desenvolvimento de estratégias, utilizando o esporte como ferramenta, para uma identidade social mais positiva do portador de deficiência física.

Palavras-chaves: Portadores de deficiência física; Atletas; Identidade social.

\section{Abstract}

It's the objective of this study to evidence the differences between the answering patterns which sustain a different perception of four distinct social categories: the non-athlete people with physical disabilities, the athletes with physical disabilities, the non-athlete people with no physical disabilities and the athletes with no physical disabilities. Where were considered the results which indicated the influence over the people with physical disabilities of being an athlete on the judgment of the participants, counting with a sample of 96 participants. It was used a comparative scheduling that allowed themselves to observe their several answers to each item. The results indicated differences of judgment between the groups, specially concerned to the athletes with physical disabilities, which were more positively evaluated than the non-athlete people with physical disabilities, and sometimes, surprising, more than the people without disabilities, evidencing an idealization and super estimating the condition of being an athlete. It is given credit that the results presented by this study can offer indications to the development of strategies using the sport as a tool for a more positive social identity of the people with physical disabilities.

Keywords: People with physical disabilities; Athletes; Social identity.

\footnotetext{
1 Mestre em Psicologia, professor da Universidade Federal da Bahia, Rua Aristides Novis, 197 Federação CEP: 40210-730 Salvador- BA, kleberfialho@yahoo.com.br

2 Doutor em Psicologia, coordenador do Mestrado em Psicologia da Universidade Federal da Bahia.
} 


\section{Apresentação}

Qualquer pessoa pode praticar esporte, desde que devidamente orientada e que o tipo de esporte praticado seja compatível com as potencialidades físicas dela. $\mathrm{O}$ espaço de convívio gerado pelo esporte é uma excelente maneira de conhecer novas pessoas e aperfeiçoar as relações interpessoais, especialmente quando o esporte é praticado em ambientes coletivos. A própria cultura dos eventos esportivos funciona como fator de sociabilidade e o esporte, praticado de maneira apropriada, absorve esse fator e é capaz de transmitir uma imagem positiva do indivíduo e do grupo de praticantes.

A mídia, muito mais por questões econômicas do que pela própria característica do esporte, reforça continuamente a imagem do atleta como herói e do esporte como símbolo de superação. Independente das razões subjacentes, a imagem pública que se tem do atleta é, na maioria das vezes, de uma pessoa forte, fisicamente saudável e capaz de exaurir todas as forças para alcançar seu ideal.

Em oposição a esta imagem visível do atleta como um quase herói, encontramos um grupo que é freqüentemente estigmatizado por suas características visíveis, os portadores de deficiência física. Quando nos deparamos com um portador de deficiência física, percebemos, quase que automaticamente, uma condição de limitação ou até mesmo incapacidade. Evitar este modo de pensamento categórico e estereotipado é fruto de um esforço cognitivo que na maioria das vezes nos impossibilita de adotar julgamentos mais igualitários. É mais fácil pensarmos o portador de deficiência física confinado em sua limitação do que visualizá-lo em atividades comuns aos não-portadores.

É preciso salientar que não é fácil definir claramente o portador de deficiência sem correr 0 risco de representações subordinadas às noções de incapacidade ou anormalidade. É preciso reconhecer que as definições utilizadas circunscrevem o conceito de deficiência pela sua condição de carência, de redução de habilidades ou de um domínio de incapacidade, que só pode ser referida por meio do contraste com um padrão de normalidade. Nas últimas décadas tem se discutido qual a terminologia mais adequada para fazer referência a alguém que se distingue pela presença de uma deficiência. Percorrendo a trajetória do conceito, pode-se identificar que ele já foi referido por termos como, por exemplo, 'inválido', 'incapacitado', 'incapaz' ou simplesmente 'deficiente'. O que existe em comum em todas estas noções é que eles compartilham uma acepção pejorativa, e mesmo expressões mais amenas, como, por exemplo, 'portadores de deficiência', ainda carregam em seu próprio âmago uma dimensão que permite antever uma certa expressão de estigmatização e discriminação.

Romeu Sassaki defende o ponto de vista de que não contamos com um termo correto e válido para denominar as pessoas que têm deficiência e sinaliza que a Convenção Internacional para Proteção e Promoção dos Direitos e Dignidade das Pessoas, patrocinada pela ONU em 1993, sugere que o nome adequado seria 'pessoas com deficiência', pois a esta expressão: 1 - não esconde ou camufla a deficiência; 2 - não aceita o consolo da falsa idéia de que todo o mundo tem deficiência; 3 - mostra com dignidade a realidade da deficiência; 4 - valoriza as diferenças e necessidades decorrentes da deficiência; 5 - combate neologismos que tentam diluir as diferenças; 6 - defende a igualdade entre as pessoas com deficiência e as demais pessoas em termos de direito e dignidade e 7 identifica nas diferenças todos os direitos que lhes são pertinentes e a partir daí encontram medidas específicas para o Estado e a sociedade eliminarem as restrições de participações. (Sassaki, 2003, p. 23)

\section{A Identidade Social dos Portadores}

Quando observamos um portador de deficiência física interagindo de forma que aparentemente faz diluir os limites a que estão sujeitos, tendemos a percebê-los como capazes de superar as adversidades, de persistir nos ideais, ainda que estas atividades possam ser aquelas que pertencem ao dia-a-dia e bastante simples para os não portadores. Uma das características mais positivamente valorizadas entre os portadores é a capacidade de superação. Freqüentemente ouvimos alusões a exemplos de superação de pessoas que foram acometidas por alguma deficiência física quando da realização de tarefas que aparentemente estariam além das suas capacidades. Muitas vezes, o portador de deficiência é julgado não pela defi- 
ciência em si mesma, mas por usar suas potencialidades e pela capacidade de superar as suas limitações.

O mais comum, no entanto, é a imposição dos atributos de dependência e incapacidade aos portadores de deficiência física, especialmente nas circunstâncias em que não possuímos nenhum outro elemento influenciando o nosso julgamento, além da visibilidade da própria deficiência.

A Teoria da Identidade Social de Henri Tajfel (1981) ressalta que os indivíduos necessitam de uma identidade pessoal e uma identidade social positiva e, desta forma, necessitam pertencer a grupos socialmente valorados. $\mathrm{O}$ pertencer a um grupo cria um "sentimento de nós" no indivíduo, a percepção de uma "personalidade coletiva". Quanto mais a pessoa se envolve com o coletivo, maior a sua identificação com ele e mais completa a sua aceitação de valores e normas do grupo. Tajfel afirma que mobilidade e mudança se apresentam como estruturas de crenças com pressupostos contrários, em que o pressuposto básico que estrutura as crenças sobre a mobilidade está apoiado na "flexibilidade e permeabilidade do sistema" e na "crença do movimento livre de uma posição social para outra, seja pela sorte, pelo mérito, pelo trabalho, pelo talento e etc.". Nesta estrutura de crença, a ação é quase sempre individual, já que está apoiada na noção de que é possível um movimento livre entre as posições e lugares na sociedade. De outra forma, temos a estrutura de crenças que sustentam as ações para a mudança social. Nesta, o pressuposto básico é o da "impossibilidade do deslocamento dado pelo cerceamento do sistema". Assim, nesta estrutura, não se permite "o movimento livre de um grupo para outra posição e a mudança é sempre articulada em conjunto com um grupo de pertença", já que assumir ser membro do grupo é o que permite 0 deslocamento grupal (Tajfel, 1984, p. 280).

Quando nos referimos a atletas portadores de deficiência física, percebemos que a imagem de atleta é potencializada e que a percepção de superar obstáculos torna-se mais positivamente valorizada. É lícito afirmar que a própria história vinculada ao desporto para portadores de deficiência reforçou uma imagem de superação e a própria prática esportiva contribui para isso. As imagens positivas são mais almejadas e servem como identificador social.
O atleta portador de deficiência apresenta um nível de superação (visto como exemplo, alvo ou objetivo) para o portador de deficiência não atleta, que passa a vê-lo como alguém dotado da possibilidade de realizar tarefas não imaginadas. Quando nos referimos aos não portadores (atletas ou não) observamos que o portador de deficiência atleta é visto, ainda que desempenhando modalidades esportivas que requerem habilidades específicas, como limitado e incapaz, quando a imagem da deficiência é mais aparente que a do esporte, um julgamento de acordo com características físicas aparentes. E algumas circunstâncias, no entanto, ocorre o inverso, a imagem de atleta suplanta a da deficiência e o portador atleta passa a ser visto de forma semelhante a um não portador.

De que forma estas diferenças nos julgamentos dos portadores e não portadores se apresentam em relação ao seu próprio grupo e ao outro grupo e em que grau se apresenta a idealização do atleta? E do portador atleta?

\section{Hipóteses}

Observaremos neste trabalho algumas tendências gerais, especificamente dois pontos principais:

1. Haverá uma tendência geral de avaliar mais positivamente os não-portadores do que os portadores;

2. Os portadores atletas serão avaliados mais positivamente do que os portadores não-atletas;

2.1 Haverá uma tendência de superestimar os portadores atletas, possibilitando avaliá-los além de sua condição física.

\section{Método}

\section{Participantes}

A amostra contou com um total de 96 participantes, tendo sido alocados por critério aleatório 24 participantes em cada grupo: portadores de deficiência física não-atletas, portadores de deficiência física atletas, não portadores de deficiência física não-atletas e não portadores de deficiên- 
cia física atletas. Todos os participantes residiam na cidade de Salvador.

\section{Instrumentos}

Para investigação das categorias-alvo do trabalho foi criado um instrumento de coleta de dados que constava de uma folha de resposta, representando, por desenhos, as quatro condições investigadas: portadores de deficiência física atletas, portadores de deficiência física não-atletas, nãoportadores de deficiência física atletas e não-portadores de deficiência física não-atletas. Mediante uma folha de registro, solicitávamos que o partici- pante da pesquisa julgasse algumas sentenças (itens) construídas a partir das respostas e das categorias elaboradas em um estudo preliminar, perfazendo um total de 24 sentenças; assim, o participante expressava sua opinião em três situações: 0 que presumia ser sua própria opinião (representada por "EU"), o que presumia ser a opinião do grupo que pertence ("NÓS") e o que presumia ser a opinião do outro grupo (“ELES")3 (anexo 1). Para cada grupo de respostas o participante utilizava um conjunto de fichas diferentes na folha de respostas com as categorias-alvo (figura 1 e anexo 2), possibilitando a comparação de suas respostas, estas, por sua vez, eram anotadas pelo pesquisador no questionário com os itens.

\section{Figura 1: Ex emplo do tabuleiro de respostas}

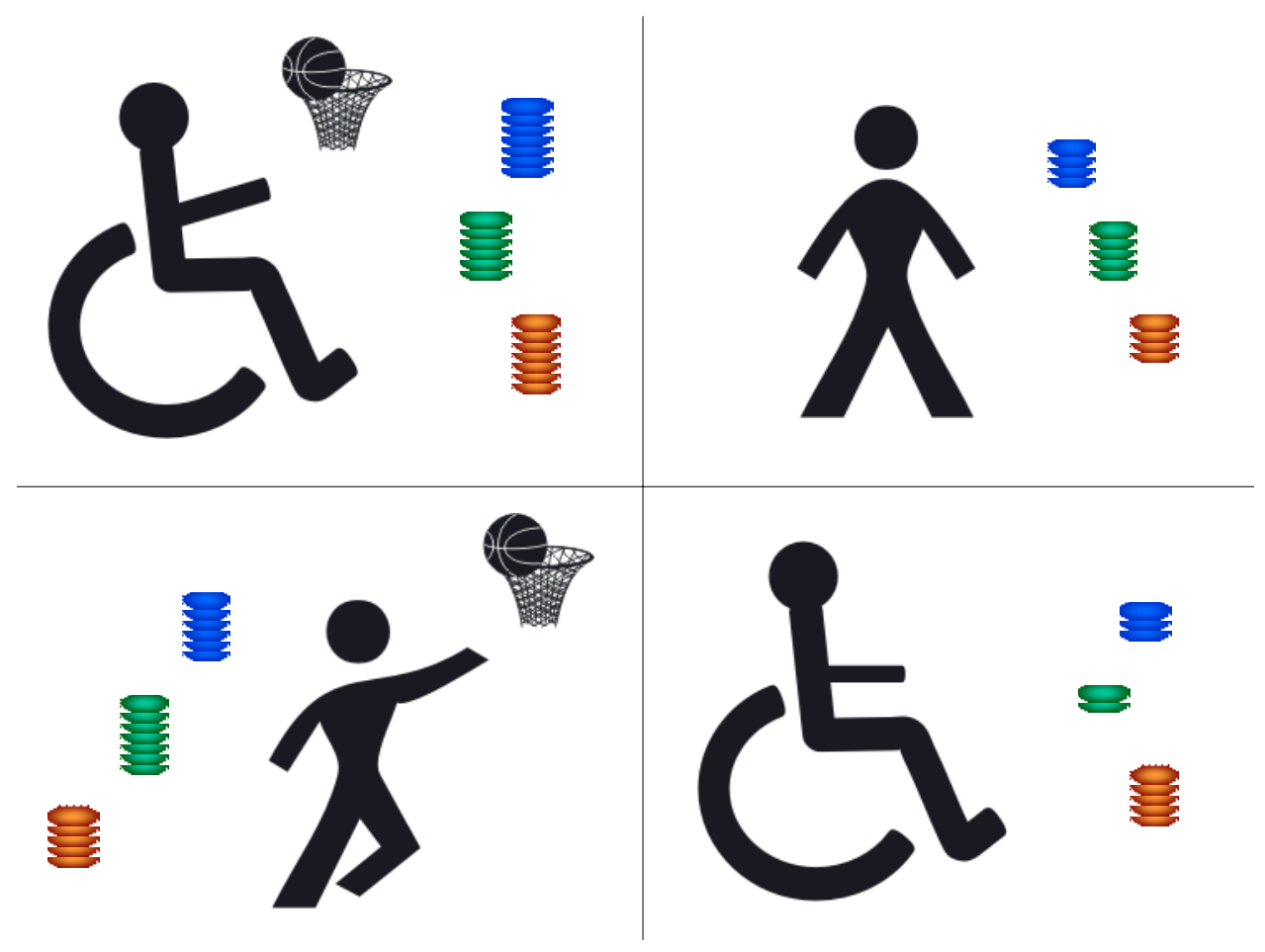

\section{Procedimentos}

A coleta de dados se realizou mediante um procedimento de escalonamento comparativo, onde o sujeito distribuiu três grupos de 20 fichas [uma de cada cor, representando sua opinião individual (eu), do seu próprio grupo (nós) e do outro grupo (eles) - considerando-se sempre o padrão de referência de grupo apenas a questão de ter ou não deficiência física] em um tabuleiro contendo os desenhos relativos aos grupos estudados (divi-

3 O conjunto de dados vinculados ao que o participante imagina ser a resposta do próprio grupo ("NÓS") e do outro grupo ( "ELES") não foi considerado em decorrência da estratégia de organização dos dados do presente estudo. 
didos em quadrantes) à medida que era interrogado pelo item em questão. As fichas foram colocadas ao lado dos desenhos representativos das categorias ao responder os itens contidos no instrumento de coleta de dados; cada grupo de cor indica um padrão de resposta em relação à opinião ("eu, nós ou eles, acham") (Figura 1 e anexo 2).

Para evitar um efeito de ordem, foram criados quatro tabuleiros com ordens alternadas das figuras. A cada item respondido pelo participante, trocava-se o tabuleiro. 0 mesmo procedimento foi realizado para a folha de respostas com os itens, alternando-se a ordem de início dos itens para cada participante.

Este instrumento comparativo permitiu aos participantes observar suas diversas respostas para cada item, comparando-as à medida que depositavam as fichas. Portanto, estes poderiam visualizar as diferenças entre cada grupo de opinião. Tal procedimento foi de fundamental importância, pois representou uma forma segura de emissão e registro das respostas, além da possibilidade de comparação entre elas.

\section{Apresentação e Discussão dos Resultados}

O esporte é uma fonte de manifestação da superação, pois, freqüentemente, exercita habilidades dificilmente reforçadas em tarefas sociais comuns e proporciona uma visão idealizada de viver intensamente, ter mais força e ser persistente. Quando nos referimos aos portadores atletas, esperamos que estas características sejam potencializadas, colocando-os em um patamar mais valorativo que as outras categorias analisadas.

Inicialmente verificamos um conjunto de respostas atreladas ao conceito de distintividade, ou seja, a possibilidade de percebermos características distintivas presentes na diferenciação das pessoas. Neste sentido, um elemento característico da deficiência física é a impossibilidade de agir de forma desapercebida. Pensando assim, os portadores não podem agir normalmente, ou pelo menos, não têm condições de agir normalmente em uma série de circunstâncias e eventos, nos quais um não-portador poderia passar sem chamar muita atenção.

Tabela 1: Médias dos portadores e não portadores e dos portadores atletas e não-atletas referentes ao item podem agir normalmente (grupo de resposta “EU”)

\begin{tabular}{|c|c|c|c|c|}
\hline Distintividade & Não-Portador & & Portador & \\
\hline Item: Podem agir & média & média & atleta & não-atleta \\
\hline normalmente & 5.90 & $4.20^{\mathrm{b}}$ & 4.59 & $3.80^{c}$ \\
\hline
\end{tabular}

${ }^{\text {b }}$ Diferença significativa entre as médias atribuídas aos não-portadores e portadores $\mathrm{p}<.001$

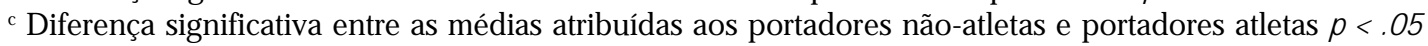

Quando comparamos as respostas referentes ao item "Podem agir normalmente", observamos diferenças significativas nos padrões de respostas julgando-se o não-portador e o portador, em que os participantes atribuíram médias mais altas para os não-portadores do que para os portadores, algo extremamente justificável pela própria característica distintiva da deficiência física (tabela 1). Quando comparamos as médias levando-se em conta o portador ser ou não atleta como alvo da opinião dos participantes, verificamos uma tendência entre eles em atribuir médias mais altas para 0 portador atleta. Assim, podemos inferir que pelo simples fato de imaginarmos o portador atleta, este poderia agir normalmente mais que o portador nãoatleta. Um julgamento idealizado pela condição estereotipada de ser atleta, uma vez que suplanta a distintividade da própria deficiência física.

Outra característica que nos chama a atenção, quando se refere à identidade social dos portadores de deficiência física, é a autonomia. Sujeitos que apresentam uma certa independência para tarefas sociais apresentam uma identidade social mais positiva em função desta autonomia, podendo diminuir o impacto de posturas preconceituosas que se fundamentam da ausência dela. Entre os portadores de deficiência física isto é bastante visível, uma vez que aquele que apresenta mais autonomia é alvo, em menor intensidade, do preconceito, não correspondendo às crenças vinculadas à deficiência física e dependência. 


\section{Tabela 2: Médias dos portadores e não portadores e dos portadores a tletas e não-a tletas referentes a conjunto de itens sobre autonomia (grupo de resposta "EU")}

\begin{tabular}{|c|c|c|c|c|}
\hline Autonomia & $\begin{array}{l}\text { Não-Portador } \\
\text { média }\end{array}$ & média & $\begin{array}{l}\text { Portador } \\
\text { atleta }\end{array}$ & não-atleta \\
\hline $\begin{array}{l}\text { Fazem qualquer atividade } \\
\text { apesar das dificuldades } \\
\text { Desempenham atividades }\end{array}$ & 4.97 & 5.03 & 5.72 & $4.33^{d}$ \\
\hline $\begin{array}{l}\text { comuns sem maiores problemas } \\
\text { Capazes de realizar tarefas }\end{array}$ & 6.5 & $3.49^{b}$ & 4.21 & $2.78^{d}$ \\
\hline da vida sem acompanhamento & 6.61 & $3.40^{b}$ & 3.94 & $2.86^{\mathrm{d}}$ \\
\hline Conquistam a independência financeira & 6.67 & $3.37^{b}$ & 3.84 & $2.91^{d}$ \\
\hline
\end{tabular}

${ }^{\mathrm{b}}$ Diferença significativa entre as médias atribuídas aos não-portadores e portadores $\mathrm{p}<.001$

d Diferença significativa entre as médias atribuídas aos portadores atletas e não-atletas $\mathrm{p}<.001$

Assim agrupamos quatro itens, que de forma explícita ou implícita se referem à noção de autonomia: "Fazem qualquer atividade apesar das dificuldades", "Desempenham atividades comuns sem maiores problemas", "Capazes de realizar tarefas da vida diária sem acompanhamento", "Conquistam a independência financeira".

Quando comparamos as médias atribuídas aos portadores e não-portadores, verificamos diferenças significativas em todos os itens, exceto no primeiro "Fazem qualquer atividade apesar das dificuldades", algo que representa uma expectativa de superação da própria deficiência, em função do conjunto de crenças presentes no julgamento de portadores de deficiência física, ou seja, é esperado que os portadores realizem qualquer atividade, um paradoxo na incidência de estereótipos que condicionam uma percepção de limitação e incapacidade. Possivelmente a sentença 'apesar das dificuldades' influencie neste julgamento.

Desta forma, quando verificamos as médias diferenciando-se o portador atleta do não atleta, observamos que se os resultados sugerem que os portadores, de modo geral, são vistos como menos capazes de alcançar uma autonomia, eles também permitem concluir que esta percepção é mais acentuada no caso dos não atletas do que no caso dos atletas. Podemos perceber esta tendência em todos os itens, possivelmente pela mesma percepção estereotipada da condição de ser atleta, porém para o item "Conquistam a independência financeira” esta crença é acentuada ou pelo menos generalizada, pois qual o alcance dessa afirmação, a se considerar que um portador dificilmente poderia se profissionalizar como atleta e buscar rendimentos para sua independência, em função da própria falta de investimento no setor e da cultura esportiva que não abre esta possibilidade. Esse resultado não teria um outro significado, sugerindo mais apropriadamente que o portador, pela natureza da própria atividade esportiva, desenvolveria habilidades ou seria dotado de atributos pessoais que o qualificaria melhor para o exercício profissional.

É evidente que outros estudos poderiam evidenciar melhor estas diferenças, todavia, é possível que as médias neste item sejam a conseqüência de uma avaliação baseada no mecanismo de superação de dificuldades para a execução de tarefas, o que é bastante comum entre os portadores de deficiência física. Supõe-se que haja uma identificação dos portadores para o item "fazem qualquer atividade apesar das dificuldades", diferenciando a percepção de seu grupo como mais capazes de fazer qualquer atividade apesar das dificuldades do que os não-portadores, sendo esta percepção potencialmente mais forte quando nos referimos ao portador atleta, como destaca Labronici, Cunha, Oliveira e Gabai (2000) na pesquisa sobre o esporte como fator de integração, "as mudanças vivenciadas por estes grupos acordou, dentro de cada deficiente físico envolvido no programa esportivo, um sentimento e vontade de melhorar o seu mundo, provando para si mesmo 
e para a sociedade que são capazes de terem soluções para suas maiores dificuldades ou barreiras" (p. 8).

Uma das opiniões mais comuns em relação ao grupo dos portadores de deficiência física está relacionada a medidas sociais mais inclusivas, possivelmente, por presenciarmos dificuldades impostas aos portadores de deficiência na sociedade. Hoje, no Brasil, milhares de pessoas com algum tipo de deficiência estão sendo discriminadas nas comunidades em que vivem ou sendo excluídas do mercado de trabalho.

Agrupamos os itens de respostas, "Têm mais chances de serem aceitos na sociedade" e "Têm maiores chances de conseguirem emprego" na expectativa de evidenciar a diferenciação de respostas entre portadores e não-portadores.

\section{Tabela 3: Médias dos portadores e não portadores e dos portadores atletas e não-a tletas referentes a conjunto de itens sobre inclusão (grupo de resposta "EU")}

\begin{tabular}{|c|c|c|c|}
\hline Inclusão & $\begin{array}{l}\text { Não-Portador } \\
\text { média }\end{array}$ & média & $\begin{array}{l}\text { Portador } \\
\text { atleta }\end{array}$ \\
\hline $\begin{array}{l}\text { Mais chances de } \\
\text { serem aceitos } \\
\text { Mais chances de }\end{array}$ & 6.96 & $3.05^{b}$ & 3.58 \\
\hline conseguirem emprego & 7.46 & $2.54^{b}$ & 2.96 \\
\hline
\end{tabular}

${ }^{\mathrm{b}}$ Diferença significativa entre as médias atribuídas aos não-portadores e portadores $\mathrm{p}<.001$

${ }^{c}$ Diferença significativa entre as médias atribuídas aos portadores atletas e não-atletas $\mathrm{p}<.05$

${ }^{\mathrm{d}}$ Diferença significativa entre as médias atribuídas aos portadores atletas e não-atletas $\mathrm{p}<.001$

É evidente, até mesmo por questões históricas, que os não-portadores devem ser mais bem avaliados que os portadores, considerando-se 0 conjunto de crenças estereotipadas presentes na categoria-alvo.

É interessante notar que quando agrupamos as respostas diferenciando-se ser ou não atleta tendo como categoria-alvo o portador, também verificamos diferenças significativas nos padrões de respostas; algo extremamente idealizado pela condição de ser atleta (avaliados mais positivamente) e que não se concretiza de forma real nas relações sociais em ser mais aceito e conseguir mais emprego.

Podemos observar se esta percepção também se generaliza quando relacionamos itens que evidenciam rejeição, isto é, se há um reconhecimento que os portadores em função da carência de situações inclusivas sejam vítimas de rejeição.

Um dos grandes problemas enfrentados pelos portadores de deficiência física é o processo de rejeição e menosprezo, que caracteriza a discri- minação. O conceito de discriminação, apesar de literalmente significar "tratar alguém de uma forma diferente", no seu sentido mais explícito, pode ser definido como um comportamento manifesto, geralmente apresentado por uma pessoa preconceituosa, que se exprime pela adoção de padrões de preferência em relação aos membros do próprio grupo e/ou de rejeição em relação aos membros dos grupos externos.

Ao observarmos os itens "Sofrem rejeição", "Detestam se sentir menosprezados", "Detestam serem humilhados", "Detestam sentirem-se inúteis", evidenciamos diferenças significativas nos padrões de respostas para as categorias portador e não-portador e verificamos que os não-portadores obtiveram uma avaliação mais positiva do que os portadores, o que é esperado, uma vez que os portadores são freqüentemente vítimas de rejeição (tabela 4).

Quando agrupamos as respostas para diferenciar as condições de atleta e não-atleta entre os portadores, não encontramos diferenças significativas entre as médias, exceto no item "Sofrem 
Tabela 4: Médias dos portadores e não portadores e dos portadores a tletas e nã o-a tletas referentes ao conjunto de itens sobre rejeição (grupo de resposta "EU")

\begin{tabular}{lllll}
\hline Rejeição & $\begin{array}{l}\text { Não-Portador } \\
\text { média }\end{array}$ & média & $\begin{array}{l}\text { Portador } \\
\text { atleta }\end{array}$ & não-atleta \\
\hline Sofrem Rejeição & 2.60 & $7.38^{\mathrm{b}}$ & 7.03 & $7.74^{\mathrm{c}}$ \\
Detestam se sentir menosprezados & 4.03 & $5.99^{\mathrm{b}}$ & 5.97 & 6.02 \\
Detestam ser humilhados & 4.53 & $5.46^{\mathrm{a}}$ & 5.60 & 5.32 \\
Detestam sentirem-se inúteis & 4.09 & $5.84^{\mathrm{b}}$ & 5.81 & 5.88 \\
\hline
\end{tabular}

a Diferença significativa entre as médias atribuídas aos não-portadores e portadores $\mathrm{p}<.05$

${ }^{b}$ Diferença significativa entre as médias atribuídas aos não-portadores e portadores $\mathrm{p}<.001$

${ }^{c}$ Diferença significativa entre as médias atribuídas aos portadores atletas e não-atletas $\mathrm{p}<.05$

rejeição", identificando que o portador atleta sofre menos rejeição que o portador não atleta. As médias referentes a este item são bem altas em comparação com as médias dos outros itens, o que evidencia que os portadores, de maneira geral, sofrem mais rejeição. Neste aspecto, parece que a condição de ser atleta não é suficiente para promover uma diferenciação das respostas, pelo menos em termos gerais.

Quando observamos o item relativo à rejeição, percebemos a incidência de médias altas considerando-se o grupo alvo portador (atleta ou não) caracterizando uma probabilidade de ações discriminatórias e atitudes preconceituosas.

A noção de preconceito refere-se a uma atitude, que seria injusta ou negativa em relação a um grupo ou a uma pessoa que se supõe ser membro do grupo. Generalizações desfavoráveis são impostas a cada um dos indivíduos que são membros de um grupo particular, sem levar em conta as diferenças individuais existentes no interior de cada grupo. Um indivíduo pode sustentar preconceitos em relação a membros de qualquer categoria social distinta da sua e pela qual experimenta sentimentos desfavoráveis.

\section{Tabela 5: Médias dos portadores e não portadores e dos portadores atletas e nã o-a tletas referentes a conjunto de itens sobre preconceito (grupo de respos- ta "EU")}

\begin{tabular}{lllll}
\hline Preconceito & $\begin{array}{l}\text { Não-Portador } \\
\text { média }\end{array}$ & média & $\begin{array}{l}\text { Portador } \\
\text { atleta }\end{array}$ & não-atleta \\
\hline Arrogantes & 6.52 & $3.48^{\mathrm{b}}$ & 3.54 & 3.43 \\
São preguiçosos & 5.48 & $4.45^{\mathrm{a}}$ & 3.21 & $5.70^{\mathrm{d}}$ \\
São imprudentes & 6.93 & $3.15^{\mathrm{b}}$ & 3.30 & 2.99 \\
São alvos de preconceito & 2.81 & $7.19^{\mathrm{b}}$ & 6.85 & 7.53 \\
São intolerantes & 6.31 & $3.69^{\mathrm{b}}$ & 3.47 & 3.91 \\
& & & & \\
\hline
\end{tabular}

\footnotetext{
Diferença significativa entre as médias atribuídas aos não-portadores e portadores $\mathrm{p}<.05$

b Diferença significativa entre as médias atribuídas aos não-portadores e portadores $\mathrm{p}<.001$

d Diferença significativa entre as médias atribuídas aos portadores atletas e não-atletas $\mathrm{p}<.001$
} 
É evidente que nenhum indivíduo desejaria ser portador de deficiência, de qualquer ordem, porém, o que se discute não é simplesmente a identificação ao grupo, mas a ter atitudes injustas e negativas (que poderiam pertencer a qualquer indivíduo em qualquer grupo social) para 0 portador de deficiência. Observamos os itens do inventário, selecionamos os que melhor expressariam tais atitudes: "arrogantes", "preguiçosos", "imprudentes" e evidentemente "alvos de preconceito" (tabela 5).

Ao agruparmos as médias dos portadores e não portadores dos itens em questão, verificamos que os portadores foram melhor avaliados do que os não portadores, exceto no item "são alvos de preconceito", o que é perfeitamente explicável, uma vez que os portadores são freqüentemente alvos de preconceito. Esta tendência de avaliar mais positivamente os portadores, de modo geral, pode representar uma atitude condescendente em relação a eles, pela própria característica dos itens.

Ser arrogante, preguiçoso ou imprudente poderia ser atribuído a qualquer indivíduo de qualquer grupo social, porém, ao julgarmos um grupo como mais que o outro (não portadores mais que portadores), verificamos a presença de elementos de categorização em função da característica física; é possível que a deficiência física proporcione uma percepção assistencialista, isto é, o portador por possuir uma deficiência física e, portanto, visível, seja suficiente para considerá-lo menos arrogante, imprudente e preguiçoso, o que representa evidentemente uma distorção de julgamento.

Quando agrupamos as respostas tendo como alvo o portador (atleta e não atleta), observamos diferenças significativas apenas no item "São preguiçosos", o que extremamente esperado, uma vez que o julgamento mais incidente na condição atlética é a idéia de vigor e disposição. Este é um dado particularmente interessante, pois, pelo menos superficialmente, percebemos que a condição atlética não se torna suficiente para a redução do estigma do preconceito, possivelmente por ser fortemente marcado na categoria de portadores, neste sentido, sobressalta a idéia ou crença dos portadores vítima de preconceitos muito mais que a possibilidade de redução deste pela identificação como atleta.

O esporte é uma fonte de manifestação da superação, pois, freqüentemente, exercita habilidades dificilmente reforçadas em tarefas sociais comuns e proporciona uma visão idealizada de viver intensamente, ter mais força e ser persistente. Quando nos referimos aos portadores atletas, esperamos que estas características sejam potencializadas, colocando-os em um patamar mais valorativo que as outras categorias analisadas.

\section{Tabela 6: Médias dos portadores e não portadores e dos portadores a tletas e não-a tletas referentes a conjunto de itens sobre superação (grupo de resposta "EU")}

\begin{tabular}{lllll}
\hline Superação & $\begin{array}{l}\text { Não-Portador } \\
\text { média }\end{array}$ & $\begin{array}{l}\text { Portador } \\
\text { média }\end{array}$ & atleta & não-atleta \\
\hline $\begin{array}{l}\text { Vivem intensamente } \\
\text { Têm mais força }\end{array}$ & 5.66 & $4.30^{\mathrm{a}}$ & 5.33 & $3.27^{\mathrm{d}}$ \\
$\begin{array}{l}\text { São persistentes quando } \\
\text { se deparam com obstáculos }\end{array}$ & 5.22 & 4.80 & 5.90 & $3.70^{\mathrm{d}}$ \\
\hline
\end{tabular}

\footnotetext{
a Diferença significativa entre as médias atribuídas aos não-portadores e portadores $\mathrm{p}<.05$

${ }^{\mathrm{b}}$ Diferença significativa entre as médias atribuídas aos não-portadores e portadores $\mathrm{p}<.001$

d Diferença significativa entre as médias atribuídas aos portadores atletas e não-atletas $\mathrm{p}<.001$
} 
Assim, ao agruparmos os itens: "Vivem intensamente", "Têm mais força", "São persistentes quando se deparam com obstáculos", podemos visualizar a manifestação de uma identidade mais positiva do portador de deficiência física atleta em relação ao portador não-atleta e como ela pode ser percebida em relação aos outros grupos (tabela 6).

Primeiramente, compararemos as respostas para os portadores e não portadores, na tentativa de verificar diferenças de avaliação, levandose em conta ser ou não portador. Observamos que nos dois primeiros itens, os não portadores foram mais bem avaliados do que os portadores, porém, quando observamos o item "São persistentes quando se deparam com obstáculos" a avaliação para os portadores foi significativamente mais alta que para os não-portadores. Possivelmente, esta distorção de julgamento ocorre em virtude de uma atitude condescendente à deficiência e também da percepção idealizada de que o portador supera mais obstáculos do que o não portador, provenientes de uma naturalização da realização de tarefas comuns à vida diária como superação de dificuldades.

Neste conjunto de respostas, já percebemos uma tendência em considerar os portadores como exemplo de persistência, possivelmente por estar atrelada à deficiência uma imagem de superação, mesmo que de fato isto não aconteça, o que pode representar uma distorção de julgamento baseada na possibilidade de se superar uma limitação.

Quando agrupamos as médias atribuídas para portadores atletas e não atletas, observamos uma idealização da condição de ser atleta, levando a uma avaliação quase duas vezes maior que a condição não-atleta. É interessante notar que até no item "vivem intensamente" essa diferença é significativa, evidenciando uma forte crença que os portadores atletas intensificam seu modo de viver. Percebemos claramente a influência da prática esportiva no julgamento dos grupos e a percepção do atleta mais positivamente avaliado, comprovando uma percepção diferenciada levando-se em conta apenas a condição de ser atleta.

Este dado é bastante relevante, pois o fato do portador ser atleta parece ser suficiente para classificá-lo como mais capaz de superar a deficiência, mostrando que a prática esportiva, para os portadores, é fundamental para uma identidade social mais positivamente valorizada.
Apesar de não representar um estudo mais aprofundado, os resultados são significativamente importantes, pois asseguram a relevância da prática esportiva na formação de uma identidade social mais satisfatória para o portador de deficiência física, o que poderia representar uma alternativa de inserção em grupos socialmente mais valorados.

É possível que, neste caso, haja um componente de identificação com a função atlética do portador, que suplanta a categoria do não-portador, um resultado não esperado, visto a pouca probabilidade disto corresponder realmente, levando a uma percepção mais positiva dos portadores atletas, caracterizando uma distorção no julgamento, pois, ser atleta, torna-se um elemento de referência para a identidade social.

Tais resultados abrem possibilidades de investigação destes julgamentos, podendo, inclusive, auxiliar na construção de práticas interventivas e processos de inclusão, uma vez que parece ser evidente uma possível influência da prática esportiva na valorização do próprio grupo e uma diferenciação na própria identidade social.

\section{Conclusão}

As pesquisas recentes em Psicologia Social mostram como os estereótipos que se encontram por trás do preconceito são um subproduto do nosso pensamento: a maneira que temos de simplificar o mundo. Ao agruparmos pessoas em categorias, exageramos a uniformidade dentro e as diferenças entre grupos. Os estereótipos têm conseqüências e fontes cognitivas, sendo resistentes à mudança, influenciando nossas avaliações do comportamento de indivíduos.

Podemos imaginar que uma série de processos - cognitivos, afetivos, motivacionais, sociais e culturais - contribui para o surgimento e desenvolvimento dos estereótipos. Entende-se que os estereótipos são superdeterminados, reconhecendo-se, ainda, a necessidade de indicar os diversos mecanismos responsáveis pela sua manifestação.

Quando consideramos o sistema cognitivo, vimos que a percepção que se tem do portador atleta, mediante um raciocínio inferencial, pode ser formada além das informações que se apresentam no plano imediato, fornecendo informa- 
ções adicionais sobre o grupo que está sendo categorizado, generalizando-se a imagem do atleta e potencializando uma identidade social mais positiva.

No plano afetivo, não podemos esquecer a influência do condicionamento clássico na formação dos afetos vinculados aos estereótipos, pois se trata de uma das formas mais primitivas de aprendizagem. Podemos suspeitar, com uma certa dose de razão, que as interações com grupos com os quais não se têm muitos contatos sejam acompanhados por afetos negativos e que, após uma série de encontros desta natureza, ao contrário de se aumentar a familiaridade, o encontro intergrupal, marcadamente desconfortável, termina por gerar sentimentos negativos e, como tais afetos tornamse associados ao grupo percebido, com o transcorrer do tempo eles passam a ser eliciados apenas pela mera referência ao grupo, sem que seja necessária a presença de qualquer indivíduo em particular para disparar a reação afetiva. Os portadores de deficiência física, por apresentarem uma característica visível e por serem minoria, tornamse alvo de possíveis associações negativas.

Por outro lado, nesta mesma linha de raciocínio, somos obrigados a reconhecer o papel desempenhado pela simples exposição a um determinado estímulo, um grupo social, por exemplo, que pode favorecer o desenvolvimento de atitudes positivas em relação àquele grupo. Assim, quando identificamos o portador como atleta, podemos imaginar que os estereótipos positivos a respeito do atleta favorecem prontamente a identidade deste grupo.

Aprendemos desde cedo que atleta é sinônimo de saúde, disposição, bem-estar e até mesmo heroísmo. Assim, numa perspectiva operante, a criança, por exemplo, é reforçada continuamente pelos pais, na execução de tarefas desejáveis, com conceitos e verbalizações do tipo de ter sido "o atleta", "o campeão" pelas finalizações destas tarefas.

Não descartando as influências dos aspectos motivacionais, mas colocando-os em um plano menos influente, percebemos que os estereótipos negativos a respeito dos portadores surgem como respostas às necessidades dos indivíduos em lidar com as inseguranças e descontentamentos vinculados à própria deficiência.

Neste sentido, um outro mecanismo capaz de afetar o desenvolvimento dos estereótipos refere-se ao plano social, no qual percebemos a tendência de utilizá-los como justificativa para a manutenção das diferenças de status entre os grupos, sobretudo o favorecimento do ingroup, o que entre os portadores atletas é muito nítido.

Entre os mecanismos culturais, principalmente referindo-se à aprendizagem social, podemos destacar, sobretudo, a influência que os meios de comunicação de massa exercem reforçando os estereótipos sobre atletas. Mais recentemente, acompanhamos uma crescente veiculação de imagens e conceitos vinculados também aos portadores atletas, principalmente relacionados às Paraolímpiadas.

Torna-se evidente a influência de ser atleta na identidade social do portador de deficiência física, porém percebemos que nos itens relacionados ao preconceito observamos que o fato de ser atleta não é suficiente para uma avaliação diferencialmente significativa dos portadores (como ocorreu em outros itens), o que pode indicar que, neste aspecto, as crenças ainda são muito fortes e incidentes no grupo alvo, considerando-se as ações proconceituosas.

Enfim, percebemos que existem múltiplos fatores que determinam a formação dos estereótipos sobre atletas portadores de deficiência física, em especial os fatores cognitivos e afetivos e que tal pesquisa, ao contrário de sugerir que os estereótipos são imunes à mudança ou mesmo supressão, oferece indicadores favoráveis, já que os resultados podem ser explicados pelo fato de que a visão dos participantes acerca do seu e do outro grupo já se encontrava bastante sedimentada, dando-nos indícios sobre o processo de estereotipização, o que pode não ser suficiente para indicar os procedimentos necessários para a redução dos estereótipos, embora saibamos que é um passo importante para que se possa avançar no conhecimento dos mecanismos que levam a uma redução destes.

\section{Referências}

Adorno, T., Frenkel-Brunswick, E., Levinson, D. J., \& Sanford, R. N. (1950). The authoritarian personality, New York: Harper.

Amaral, Lígia A. (1996). Deficiência: Questões conceituais e alguns de seus desdobramentos. Cadernos de Psicologia, (1), 03-12. 
Allport, G. W. (1962). La naturaleza del prejuicio. Buenos Aires: Eudeba.

Aranha, Maria S. F; Rodrigues \& Maria M. P. (1993). O portador de deficiência física: caracterização de sua identidade social. Revista Cultura UFES, (47), 49-56.

Bar-Tal, D., Graumann, C. E., Kruglanski, A. W., \& Stroebe, W. (Eds.). (1989). Stereoyping and prejudice: Changing conceptions. New York: Springer-Verlag.

Barboza, F. V. \& Beraldo, V. (2003). Inclusão necessária. São Paulo: Proteção.

Bourhis, R. Y. \& Leyens, J. P. (1996). Estereotipos, discriminacion y relaciones entre grupos. Madrid: McGraw-Hill.

Carvalho, E. N. (1997). Deficiência mental. Brasília: SEESP.

Comitê Paraolímpico Brasileiro (2005). Recuperado em 20 de janeiro de 2005 de www.cpb.org.br.

Consolidação das Leis do Trabalho (CLT). Recuperado em 25 de novembro 2001 de https:// www.planalto.gov.br/ ccivil_03/Decreto-Lei/

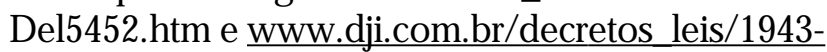
005452-clt/clt.htm.

Coordenadoria Nacional para a Integração da Pessoa Portadora de Deficiência - CORDE. Recuperado em 12 de setembro de 2002 de www.mj.gov.br/ sedh/ct/corde/dpdh/corde/principal.asp

Cunha, C. F. (2001). Dicionário etimológico da língua portuguesa. Rio de Janeiro: Fename.

D’Amorim, Maria Alice M. (1988). Psicologia: reflexão e crítica. Porto Alegre, 3(1/2), 3-11.

Duckitt, John. (1992 October). Psychology and prejudice, a historical analyses and integrative framework. American Psychologist, 47 (10) 11821193.

Fialho, K. L L, \& Pereira, M. E. (2005). Estereótipos sobre atletas portadores de deficiência física, Dissertação de Mestrado, UFBA, Salvador.
Labronici, R. H., Cunha, M. C., Oliveira, A. S. \& Gabbai, A. (2000). Esporte como fator de integração do deficiente físico na sociedade. Arq. Neuro-Psiquiatria, 4(58),1092-1099.

Novaes, M. Helena (1982). Significado psicológico da deficiência e recíproca adaptativa entre pessoas deficientes e não deficientes. Arquivos Brasileiros de Psicologia, 34(3), 195-196.

Omote, S. [2000?]. A deficiência como fenômeno socialmente construído. Comunicação na 11 semana da faculdade de educação, filosofia, ciências sociais e documentação da UNESP/Marília. Marília, mimeo.

Pereira, Marcos E. (2002). Psicologia social dos estereótipos. São Paulo: E.P.U.

Saeta, Beatriz R. P. (1999). O contexto social e a deficiência. Psicologia Teoria e Prática, 1(1), 5155.

Sassaki, R. K. (2003). Vida independente (coletânea de artigos). São Paulo.

Tajfel, H. (1978). Differentiation between social groups: studies in the social psychology of intergroup relations. London: Academic Press.

Tajfel, H. (1981). Social stereotypes and social groups. In Turner, J. \& Giles, H. (Eds.) Intergroup behaviour. Oxford: Basil Blackwell.

Tajfel, H. (1982). Social psychology of intergroup relations. Annual Review of Psychology, 33, 139.

Tajfel, H. (1984). Grupos humanos e categorias sociais (Vols 1-2). Lisboa: Livros Horizonte.

Recebido em/received in: 17/05/2006 Aprovado em/approved in: 30/05/2006 